\begin{tabular}{|c|c|}
\hline PORT SAID ENGINEERING RESEARCH JOURNAL \\
Faculty of Engineering - Port Said University \\
Volume17 No. 2 September $2013 \mathrm{pp}: 30-40$
\end{tabular}

\title{
Effect of Opposed Lateral and Vertical Eccentricity on Free Convection in an Elliptical Annulus Enclosure in Blunt and Slender Orientations
}

\author{
Eid. E. I. ${ }^{1}$, Halim M. A. ${ }^{1}$ and Easa. A. S. ${ }^{1}$
}

\begin{abstract}
This paper presents an investigation for the effect of opposed lateral and vertical eccentricity on free convection in an elliptical annulus enclosure in blunt and slender orientations. Three test specimens of elliptical cy linders having an equal radius ratio and an equal length were prepared for this purpose. The outer surface area of the inner elliptical cylinder is the same for each specimen as well as the area of the inner surface of the outer elliptical cylinder for each specimen. Different elliptical ratios of $0.662,0.866$ and 0.968 were investigated. The specimens were cut using the computed numerically controlled wire-cut machining. Experimental tests were done by maintaining constant heat flux on the inner cylinder and the outer one was exposed to approximately constant temperature of the closed laboratory. Both annuals ends of the annular elliptical cylinders were closed by cork to form the annular enclosure space. The experimental tests scanned the modified Rayleigh number $\left(1.642 \times 103 \leq \mathrm{Ra}^{*} \leq 3.849 \times 106\right)$. The effects of the opposed vertical eccentricity, opposed lateral eccentricity on free convection for both blunt and slender orientation were investigated. Empirical correlations were deduced within an acceptable uncertainty for the experimental results. Compatible and satisfactory to the conscience agreement was found in a comparison among the results of present and previous works. In the vision of the comparison, it was found that; the convective heat transfer for the opposed vertical eccentricity is greater than the convective heat transfer for the lateral opposed eccentricity in slender orientation by about $40 \%$ from concentric. The convective heat transfer for the opposed lateral eccentricity is greater than the convective heat transfer for the vertical opposed eccentricity in blunt orientation by about $30 \%$ from concentric. Slender orientation offers about $50 \%$ enhancement in free convection than the blunt situation for the same elliptical ratio.
\end{abstract}

\section{NOMENCLATURE}

Symbols Description

A Surface area

a Semi-major axis

b Semi-minor axis

Gr Grashof of number

g Gravity acceleration

h Heat transfer coefficient

I Electric current

k Thermal conductivity

L Cylinder length

$\mathrm{Nu} \quad$ Local Nusselt number

Pr Prandtl number

Q Heat transfer rate

q" Heat flux

$r \quad$ Radius

Ra Modified Rayleigh

Ra* Modified Rayleigh

T Temperature

t Cylinder wall thickness

$\mathrm{V}$ Voltage

\section{Greek letters}

$\begin{array}{ll}\text { Symbols } & \text { Description } \\ \beta & \text { Volume coefficient of } \\ \delta & \text { Eccentricity, } \\ \varepsilon & \text { Surface emis sivity } \\ \phi & \text { Angle of attack, }\end{array}$

${ }^{1}$ Mechanical Department, Faculty of Industrial Education, Suez University, Egypt

W $\mathrm{W} / \mathrm{m}^{2}$

$\mathrm{m}$

\begin{tabular}{|c|c|c|c|}
\hline $\begin{array}{l}\text { Unit } \\
\mathrm{m}^{2}\end{array}$ & $\lambda$ & $\begin{array}{l}\text { vertical gap width } \lambda=b_{0}-b_{i} \text { for } \\
\text { blunt } \lambda=a_{0}-a_{i} \text { for slender }\end{array}$ & $\mathrm{m}$ \\
\hline $\mathrm{m}$ & $\vartheta$ & Kine matical viscosity & $\mathrm{m}^{2} / \mathrm{s}$ \\
\hline $\mathrm{m}$ & $\sigma$ & Stefan-Boltzmann constant & $\mathrm{W} / \mathrm{m}^{2} \mathrm{~K}^{4}$ \\
\hline $\begin{array}{l}\mathrm{m} / \mathrm{s} \\
\mathrm{W} /\left(\mathrm{m}^{2} \cdot \mathrm{K}\right)\end{array}$ & $\omega$ & $\begin{array}{l}\text { Horizontal gap width } \omega=a_{0}-a_{i} \\
\text { for blunt } \omega=b_{0}-b_{i} \text { for slender }\end{array}$ & $\mathrm{m}$ \\
\hline Ampere & $\xi$ & Elliptical ratio $\xi=\sqrt{1-\left(b^{2} / a^{2}\right)}$ & \\
\hline
\end{tabular}

\section{Subscripts}

Symbols Description

$\begin{array}{cl}\text { a } & \text { Air } \\ \text { avg } & \text { Average } \\ \text { cond } & \text { Conduction regime } \\ \text { conv } & \text { Convection regime } \\ \text { e } & \text { End-section } \\ \mathrm{f} & \text { Film } \\ \mathrm{i} & \text { Inner cylinder } \\ \mathrm{l} & \text { lateral } \\ \mathrm{m} & \text { Mid-section } \\ \mathrm{o} & \text { Outer cylinder } \\ \mathrm{rad} & \text { Radiation regime } \\ \mathrm{s} & \text { Solid } \\ \mathrm{t} & \text { Total } \\ \mathrm{v} & \text { Vertical }\end{array}$




\section{INTRODUCTION}

The natural convection heat transfer in annular spaces is the subject of many numerical and experimental studies because of their great importance in many industrial applications. The free convection heat transfer between circular and elliptical annuluses becomes important in recent decade due to its numerous associations with; geothermal systems, insulations and flooding protection for buried pipes used for district heating and cooling, nuclear reactors, space heating, refrigerator condensers, heating of oils for ease of pumping, heat exchangers, passive solar energy collectors, crude oil production, electronics cooling, fibre and granular insulations, solidification in casting and many of machining processes, underground electric transmission cables using pressurized gas and others. Recently, many investigations for such problems are being performed.

Free convection heat transfer between two elliptical cylinders having different elliptical ratios was studied experimentally by Eid [1]. In this study three pairs of elliptical cylinders having the same radius ratio, the same surface area and different elliptical ratio were tested experimentally. The tests were carried out by keeping a constant heat flux on the inner cylinder while cooling the outer one to be is othermal. It was found that; the vertical eccentricity can enhance free convection by about $15 \%$ than the concentric case, the horizontal eccentricity can enhance natural convection by about $10 \%$ than concentric case and slender situation offers about $40 \%$ enhancement in free convection than the blunt situation for the same elliptical ratio. The influence of various Prandtl numbers on the laminar convection flow between concentric and vertically eccentric cylinders was studied numerically by Projahn and Beer [2]. Two independent computer programs based on different formulations of the governing equations were used. Local heat transfer results were presented for a wide range of Rayleigh numbers. Laminar free convection heat transfer from an array of horizontal isothermal elliptic cylinders with major axis vertical has been experimentally investigated by Yousefi and Ashjaee [3]. Experiments were carried out using Mach-Zehnder interferometer with the cylinder spacing from two to five cylinder major axis. It is found that the free convection heat transfer from any individual cylinder in the array depends on Rayleigh number, cylinders separation distance and cylinder position in the array. Natural convection heat transfer in eccentric annuli that were prepared from two isothermal horizontal circular cylinders was numerically investigated by Suofang [4]. It is found that, in general, theequivalent thermal conductivity $\left(\mathrm{k}_{\mathrm{eq}}\right)$ increases as $\mathrm{Ra}$ increases, and the plume flow will be unsteady at the upper annuli when Ra $>2.02 \times 10^{4}, \mathrm{k}_{\mathrm{eq}}$ increases as $\mathrm{D}_{\mathrm{o}} / \mathrm{D}_{\mathrm{i}}$ and $\mathrm{Pr}$ increase, There a critical value of eccentricity existed $\left(\delta_{\mathrm{cu}}=0.6\right)$ when $\delta>$ $\delta_{\mathrm{cu}}, \mathrm{k}_{\mathrm{eq}}$ slightly decreases as $\delta$ increases; when $\delta>\delta_{\text {cru }}, \mathrm{k}_{\mathrm{eq}}$ increases rapidly as $\delta$ increases before $\delta_{\mathrm{cm}}$. $\mathrm{k}_{\mathrm{eq}}$ increases monotonously as $\theta_{\mathrm{p}}$ increases from $0^{\circ}$ to $180^{\circ}$. Natural convection heat transfer between a horizontal cylindrical envelope and an internal concentric heated square cylinder with two slots was experimentally studied by Li[5]. The ratio of slot width $\mathrm{S}$ to the side height $\mathrm{H}$ was
0.0612 and 0.3878 . The ratio of the envelope inner diameter $D_{o}$ to the side height $H$ was 2.653. It was found that; the heat transfer enhancement of the slotted cases over the non-slotted cases has a quite significance. An experimental investigation was carried out for free convection of air around the outer surface of an elliptic tube having aconstant heat flux by Amr [6]. The local and average Nusselt number distribution was reported for differentvalues of Rayleigh number and different tube inclination angles. It is found that; a higher value of average Nusseltnumber was achieved when the major axis of the tube is vertical. Natural convection in a horizontal cylindrical gap for hot tubes of small diameters was studied numerically byBerkengetm [7]. The effect of the diameter of the hot cylinder on the rate of natural convection during heat transmission through horizontal cylindrical-annular gaps was analyzed. The heat was supplied from an inner hot cylinder through a fluid (distilled water or $96 \%$ ethanol) to an outer cylinder. It was found that; the convection heat transfer coefficient has been related not only to the Rayleigh number but also to the geometrical dimensions (diameter of the hot tube and relative gap width). Free convection boundary layer flow driven by temperature gradients near a permeable horizontal cylinder of elliptic cross-section with constant wall temperature in a fluid-saturated porous medium was studied numerically by Ching[8]. The heat transfer rates of the elliptical cylinder withslender orientation in porous media were found to be higher than those with blunt orientation. Experimental and numerical studies for natural convection in two dimensional region formed by a constant heat flux horizontal elliptic tube concentrically located in a larger, isothermally cooled horizontal cylinder were investigated by Sakr[9]. Both ends of the annulus are closed. Experiments were carried out $1.12 \times 10^{7} \leq \mathrm{Ra} \leq 4.92 \times 10^{7}$. The elliptic tube orientation angle varies from $0^{\circ}$ to $90^{\circ}$. The experiments were carried out for axis ratio of elliptic tube of 1:3. The results showed that; the average Nusselt number increases as the orientation angle of the elliptic cylinder increases from $0^{\circ}$ to $90^{\circ}$ and with Rayleigh number as well.Numerical solutions were presented for steady laminar twodimensional natural convection in concentric and eccentric horizontal cylindrical annuli with constant heat flux on the inner wall and a specified isothermal temperature on the outer wall by Ho[10]. Results revealed that; the influence of the Prandtl number is quite weak. Above all Natural convective heat transfer between two horizontal elliptic cylinders was numerically studied byZhu [11]. The study was validated by comparing results with available publication data and very good agreement has been achieved. Experimental and numerical simulation study for natural convection heat transfer formed by uniformly heated horizontal elliptic and circular cylinders concentrically located in an isolated horizontal cylinder were investigated by [12]. Both ends of the annulus were opened. The experimental results showed that the heat transfer process improves as Grashof number increases and is better in elliptic annulus than circular annulus. The reduction in the cross-section area causes reduce in the free convection heat transfer. The 
reduction in the natural convection in the elliptic annulus decreases as the major axis rotates from $\psi=0^{\circ}$ to $\psi=90^{\circ}$. Steady two-dimensional problem of laminar free convection from an inclined elliptic cylinder for small Grashof numbers was studied by Pascal [13]. The results demonstrate that the steady and limiting unsteady flows are in good agreement near the cylinder surface while interesting departures occur in the far-field.

From previous review, it is clear that, there is a lack in the investigation of free convection through an elliptical annuals enclose. The aim of the present work is to highlight this subject in more details.

\section{EXPERIMENTAL WORK}

The experimental test rig was elaborated at Faculty of Industrial Education Suez University, Suez Egypt. The experimental test rig mainly consists of three test specimens. Every one consists of a pair of elliptical cylinders having an equal radius ratio and an equal length. The test rig has a group of attachments that facilitate the target of the experimental work.

\subsection{Test Specimen}

Each test specimen has a pair of elliptical cylinders; an outer elliptical cylinder and inner elliptical one. The pair of elliptical cylinders having an equal radius ratio of 2.0 and an equal length of $0.25 \mathrm{~m}$. The test specimens were cut from aluminium by using the computed numerically controlled wire-cut machining (JSEDM). Each test specimens has the main dimensions listed in the table(1):

Table 1 main dimensions of the three test s pecimens.

\begin{tabular}{|c|c|c|c|c|c|}
\hline $\begin{array}{c}\text { Test specimen } \\
\text { NO }\end{array}$ & $\begin{array}{c}a_{i} \\
(\mathrm{~mm})\end{array}$ & $\begin{array}{c}a_{o} \\
(\mathrm{~mm})\end{array}$ & $\begin{array}{c}b_{i} \\
(\mathrm{~mm})\end{array}$ & $\begin{array}{c}b_{o} \\
(\mathrm{~mm})\end{array}$ & $\xi$ \\
\hline I & 28.57 & 57.14 & 21.42 & 42.86 & 0.663 \\
\hline II & 33.33 & 66.67 & 16.66 & 33.33 & 0.866 \\
\hline III & 40.00 & 80.00 & 10.00 & 20.00 & 0.968 \\
\hline
\end{tabular}

\subsection{Test rig}

The experimental test rig shown in Fig. 1 contains a test specimen, a heating system as an elliptical heater; a measuring system consists of a voltmeter, an ammeter, an auto-transformer. Each test specimen was oriented horizontally either blunt (major axes are horizontal) or slender (major axes are vertical). Different opposed lateral and vertical eccentricity were investigated. To adjust eccentricities, a protector was provided. The outer cylinder was fixed by two holders at its ends. It was kept horizontal by the two holders using a water levelling device, either as blunt or slender orientations. However, the inner one was carried by a rotated U-holder about two pivots in two positions at the mid-point of the length of the frame. When the U-holder rotates about a horizontal axis, one end of the inner cylinder goes up and the other comes down to make the opposed vertical eccentricity, when the U-holder of the inner cylinders rotates about vertical axis one end of the inner cylinder goes left and the other comes right to make the opposed lateral eccentricity. Experimental tests were done by maintaining constant heat flux on the inner cylinder and the outer one was exposed to approximately constant temperature of a closed laboratory. Both annuals ends of the annular cylinders were closed by cork to form the annular enclosure space. Twenty six K-type thermocouples were used to measure the temperature in different locations. Nine thermocouples were used to measure the temperatures of the outer surface of the inner cylinder as shown in Fig. 3 They were situated on three sections, three-ones on each section with $120 \mathrm{o}$ between them with a revolving an angle of $40 \mathrm{o}$ between two successive sections. Other twelve thermocouples were used to measure the temperature of the inner surface of the outer cylinder as shown in Fig. 2, threeones on each section with $90 \mathrm{o}$ between them with a revolving an angle of $30 \mathrm{o}$ between two successive sections Four thermocouples were used to measure the air temperature inside annular gap between the cylinders. One thermocouple measures the room temperature of the closed laboratory. The power consumed by the heater was calculated by both voltage and resistance of the heater coil. The voltage was measured using a voltammeter while the resistance was measured by using a multimeter A digital temperature indicator (Manufacturer: Digital Multimeter, Model: EM5511, Ktype) of $0.1 \mathrm{oC}$ resolution was used to record the temperature. To check up the power consumed by the heater, the current was measured by an ammeter of $100 \mu$ Ampere resolution and a voltmeter of $10 \mathrm{mV}$ volt resolutions. 


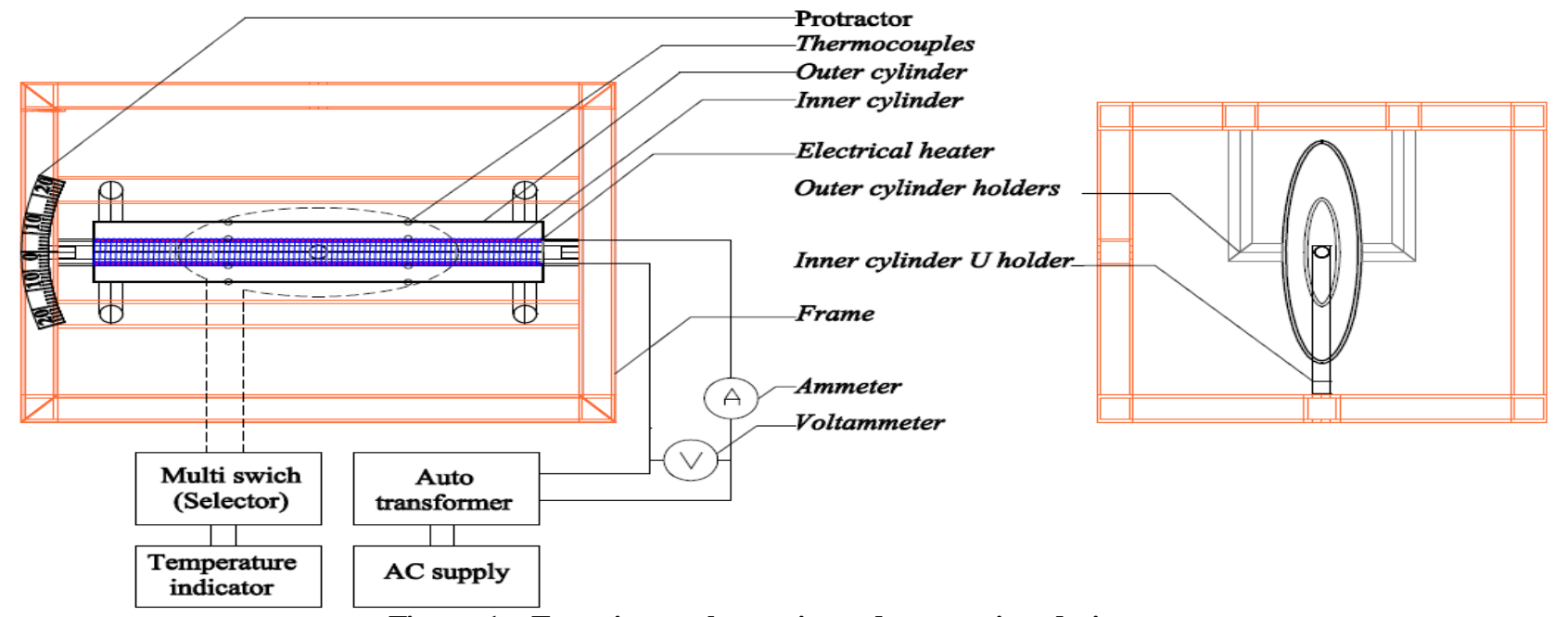

Figure 1 : Experimental test-rig and measuring de vices.
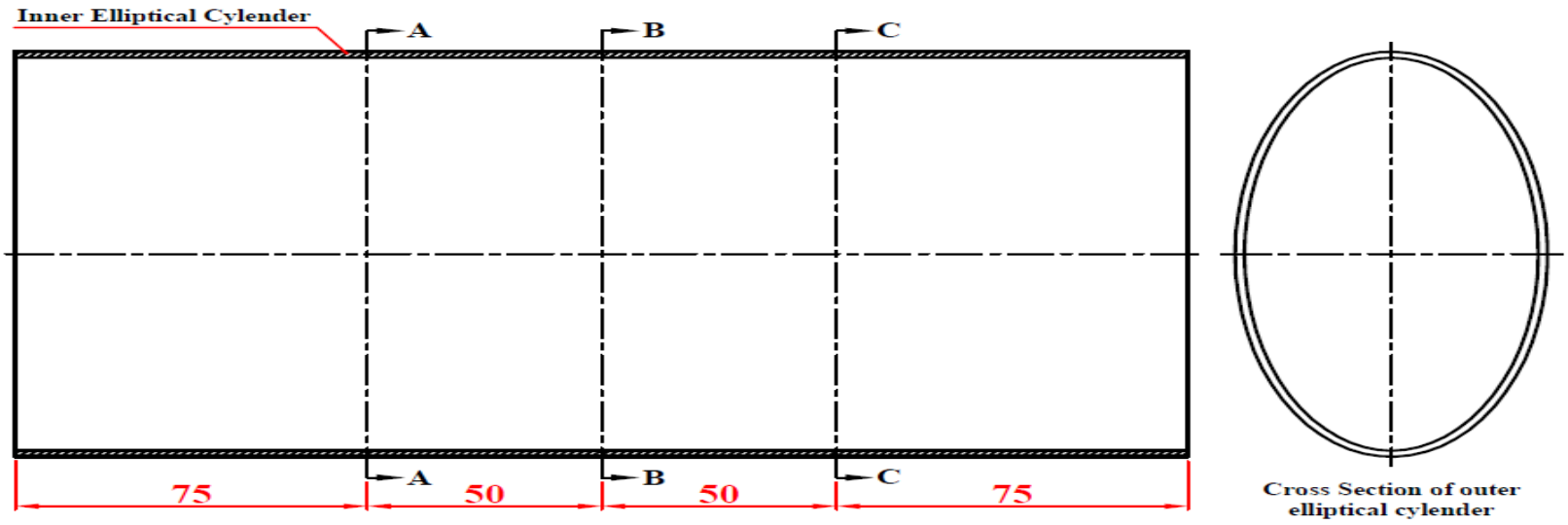

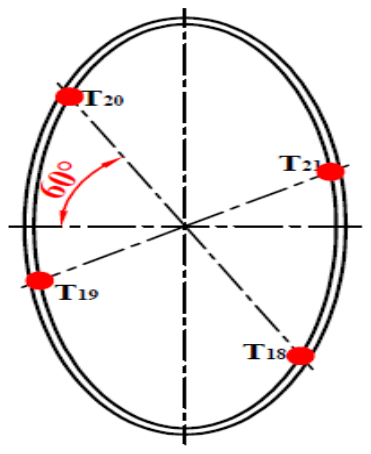

Section at $\mathbf{A}-\mathbf{A}$

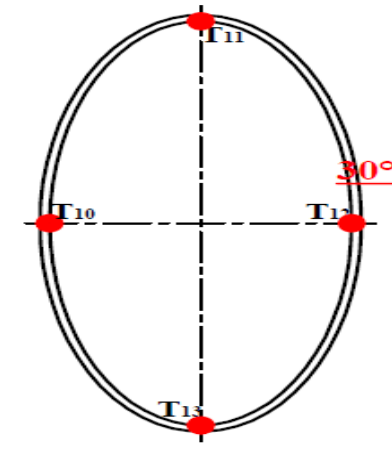

Section at $\mathbf{B}-\mathbf{B}$

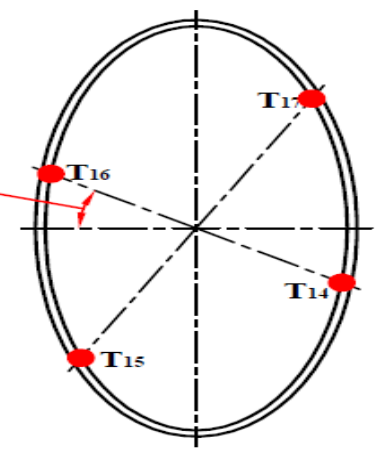

Section at $\mathrm{C}-\mathrm{C}$

Figure 2 : The location ther mocouple on outer elliptical cylinder. 


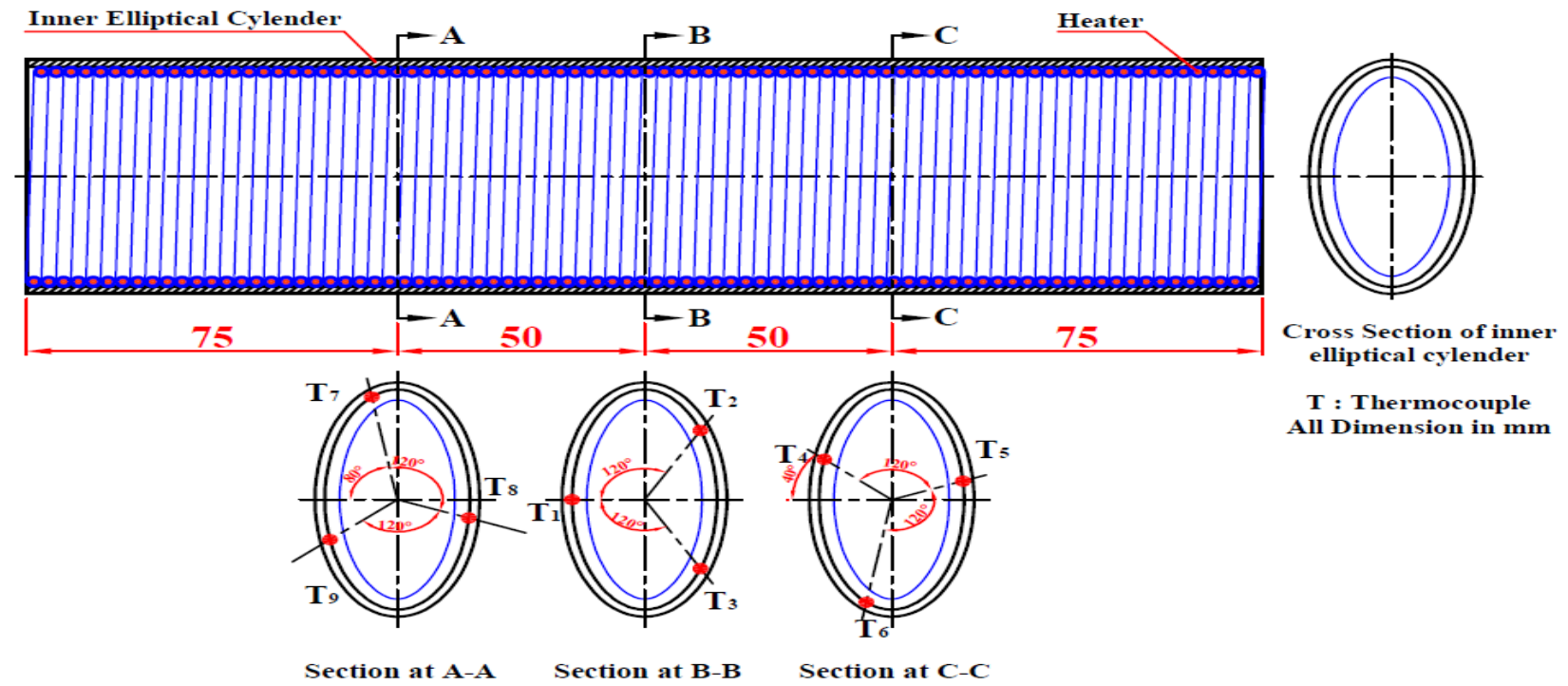

Figure 3 : The location ther moc ouple on inner elliptical cylinder.
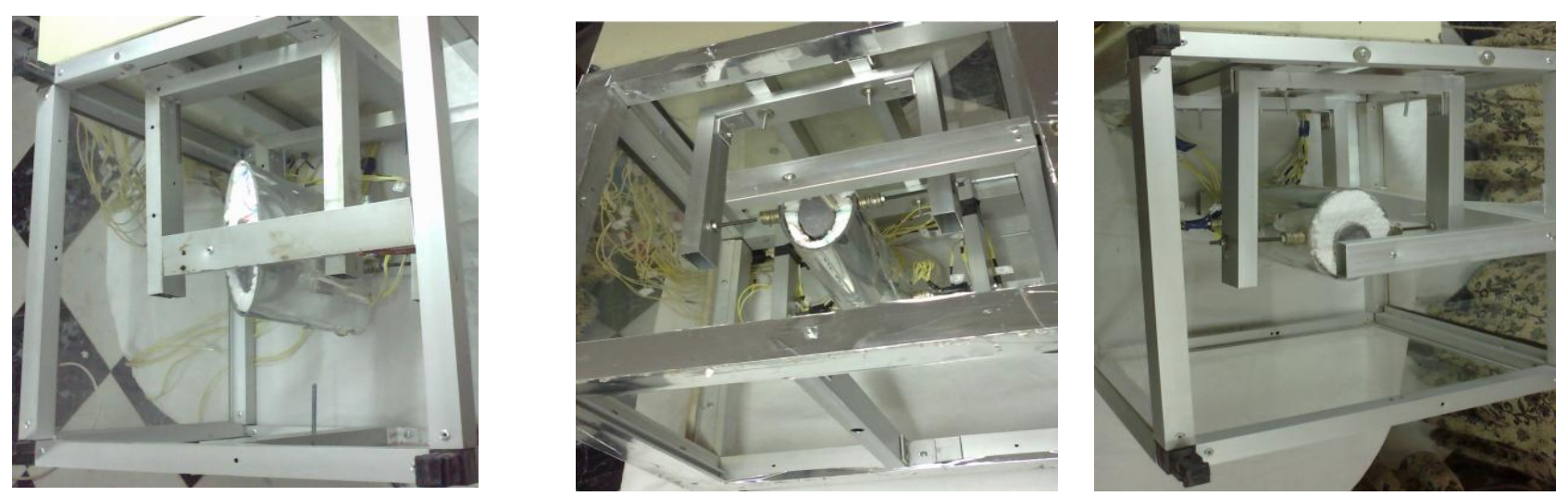

Figure 4 : photographs of the three test s pecimen.

\subsection{Experimental Program}

Referring to Fig.4, each test specimen was tested alone for orientation modes shown in figure.4, 5:

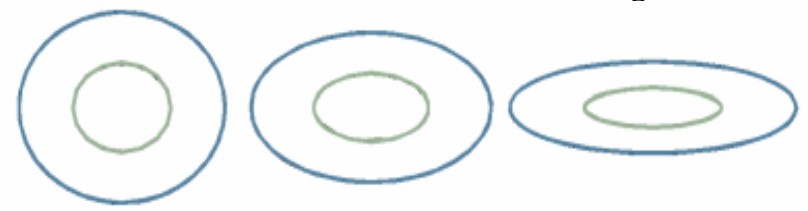

(a) Concentric
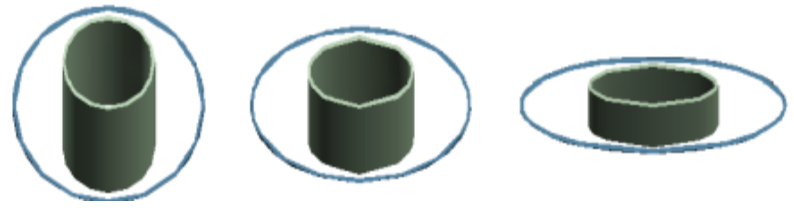

(b) Opposed vertical eccentricity
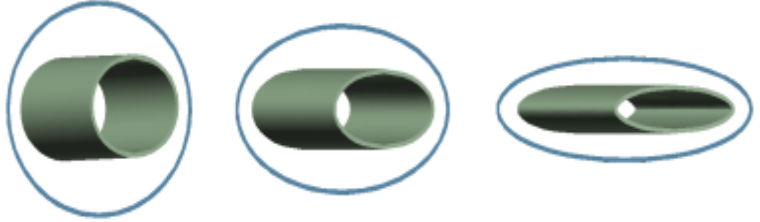

(c) Opposed lateral eccentricity

Figure 5 :The Frontal view of blunt orientation
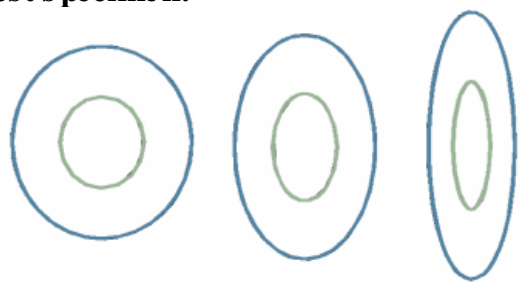

(a) Concentric
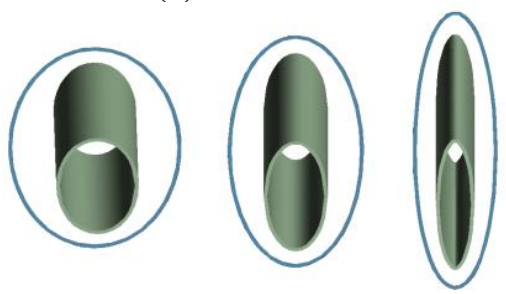

(b) Opposed vertical eccentricity
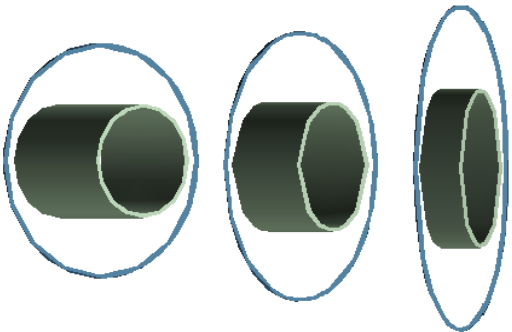

(c) Opposed lateral eccentricity

Figure 6 ; The Frontal view of slender orientation. 
The range and the parameters to be studied are as follows:

- Elliptical ratio: $0.662 \leq \xi \leq 0.968$

- Opposed vertical eccentricity: $\pm 0.25 \leq \delta_{\mathrm{v}} / \lambda \leq \pm 0.75$

- Opposed lateral eccentricity: $\pm 0.25 \leq \delta_{\mathrm{L}} / \omega \leq \pm 0.75$

- Rayleigh Nu mber $8.529 \times 10^{2} \leq \mathrm{Ra}^{*} \leq 3.628 \times 10^{6}$

The steady-state condition was verified after about five to six hours depending on the values of heat flux. To confirm this, the maximum temporal and spatial variations in temperature reading was set to be $\pm 0.1^{\circ} \mathrm{C}$ during 15 mints as a criterion of steady state condition.

\section{EXPERIMENTAL DATA REDUCTION}

The heat transfer by free convection between elliptical annuals is $[1,12]$ :

$$
\begin{aligned}
& Q_{\text {conv }}=Q_{\dot{t}}-Q_{\text {rad }}-Q_{\text {cond }}=V I-Q_{\text {rad }}-Q_{\text {cond }}=q A_{i}(1) \\
& Q_{\text {rad }}=\sigma A_{i} \varepsilon_{i}\left(T_{i, a v g}^{4}-T_{a}^{4}\right)+\left[\frac{\sigma A_{i} \varepsilon_{i}\left(T_{i, a v g}^{4}-T_{o}^{4}\right)}{\left.\frac{1}{\varepsilon_{i}}+\frac{1-\varepsilon_{O}}{\varepsilon_{i}}+\frac{a_{i}-b_{i}}{a_{o}-b_{o}}\right](2)}\right. \\
& Q_{\text {cond }}=\frac{4 \pi\left(a_{i}+b_{i}\right) t\left(T_{m}-T_{e}\right)}{\frac{L}{2 k_{s}}}(3) \\
& h=\frac{Q_{\text {conv }}}{\pi\left(a_{i}+b_{i}\right) L\left(T_{i, a v g}-T_{O}\right)}=\frac{q^{\prime \prime}}{\left(T_{i, a v g}-T_{O}\right)}(4) \\
& N u=\frac{h \lambda}{k}(5) \\
& R a^{*}=\frac{g \beta q \lambda^{4}}{k \vartheta^{2}} \operatorname{Pr}(6)
\end{aligned}
$$

\section{RESULTS AND DISCUSSION}

Results will be provided as dimensionless groups (Ray leigh number and Nusselt number). The results from the three test specimens in slender orientation will be provided as well as the corresponding results from the specimens in blunt orientation.

\subsection{Slender orientation}

Referring to figure $(7,8,9,10)$; the opposed eccentricity results increases convective heat transfer. This is attributes to the heterogeneous temperature distribution on both outer surfaces of the inner elliptical cylinder and inner one of the outer one. The heterogeneity produces an additional perpendicular circulatory to the cross section of the test specimen. The crossing of both circulators parallel and perpendicular to cross section creates turbulence regions in the enclosure and as a consequence the convective heat transfer increases. The rapid circulatory of the air plume in the enclosure resulted from the low resistance to the upward driven plume as seen for specimen No. 3. The low resistance is resulted from the minimum blockage ratio for the small value of minor axis. The velocity of the upward plume reduces gradually as the blockage ratio increases due to the increase of minor axis as seen from the results of specimen No. I and II. The higher opposed eccentricity has a significant increase in the convective heat transfer in slender orientation (vertical eccentric, lateral eccentric). As well as the comparison among vertical opposed eccentric and lateral opposed eccentric for each test specimens in slender orientation gives the same tendency, as clear in figures $(7,8,9)$ that the convective heat transfer for the vertical opposed eccentricity is greater than the convective heat transfer for the lateral opposed eccentricity by about $40 \%$ from concentric. The comparison among the maximum vertical opposed eccentricity $(\delta=0.75 \lambda)$ for three test specimens in slender orientation, figure 10 , shows that the convective heat transfer for test specimen No. III is the greatest one.

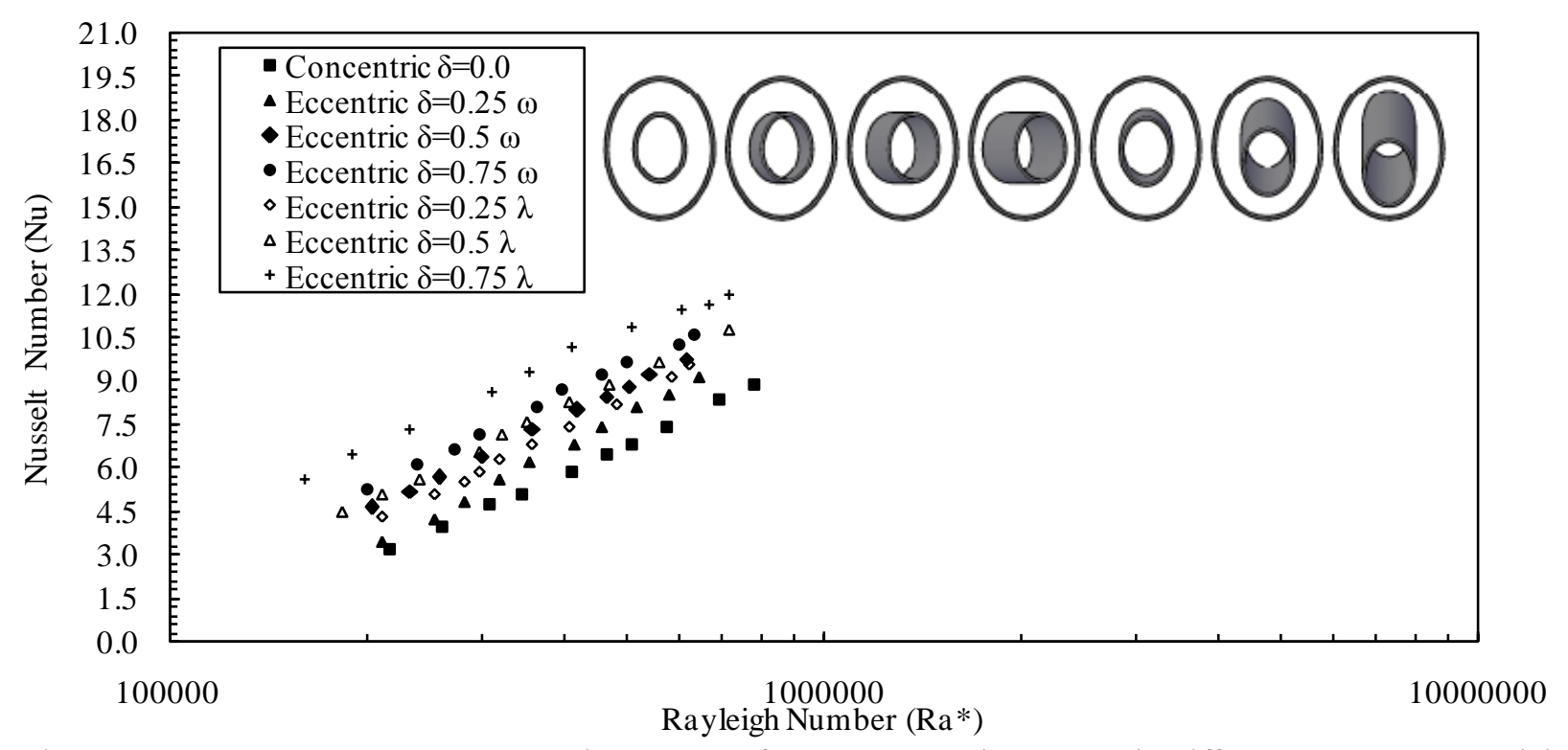

Figure 7 : Nusselt number versus Rayleigh number for the test specimen No. I in different opposed ecentricity for slender orientation. 


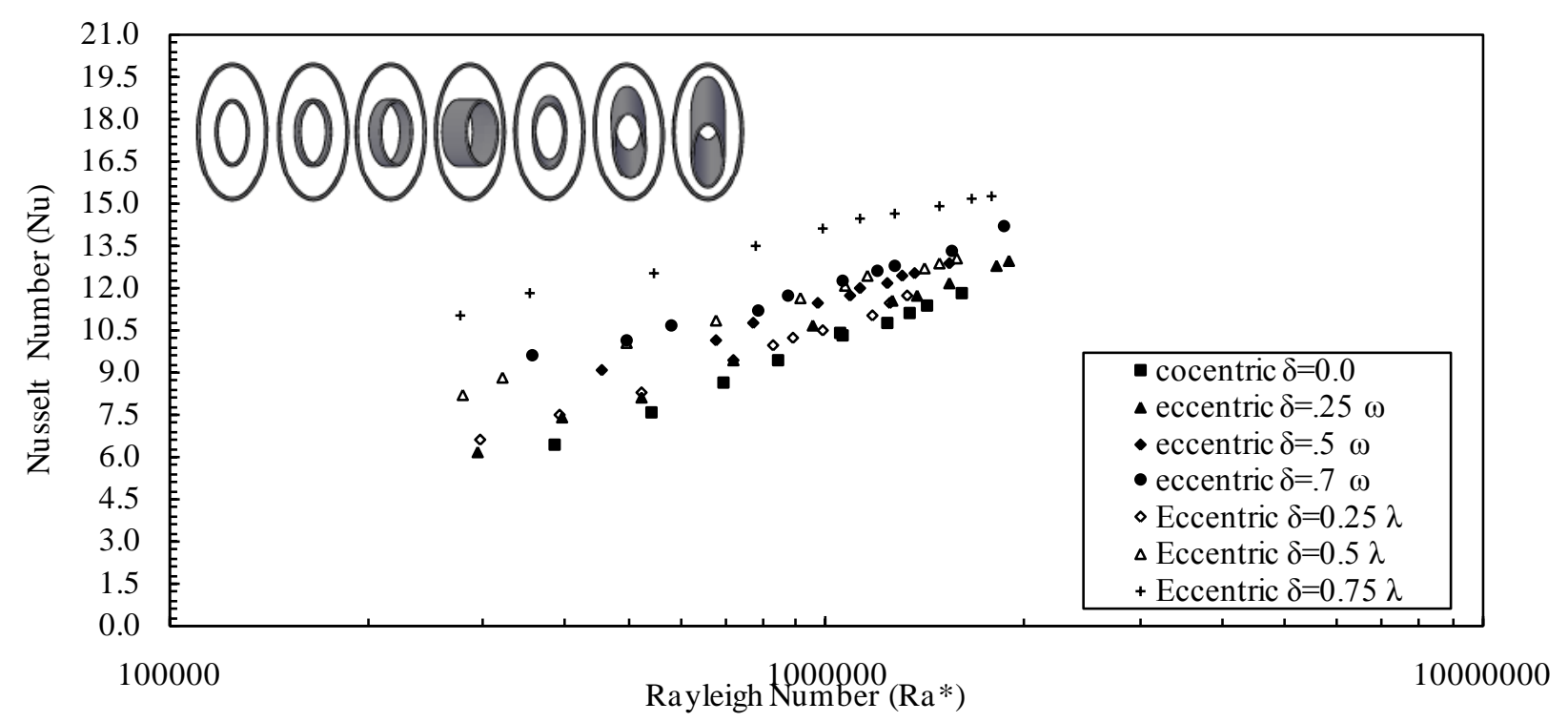

Figure 8: Nusselt number versus Rayleigh number for the test specimen No. II in different opposed eccentricity

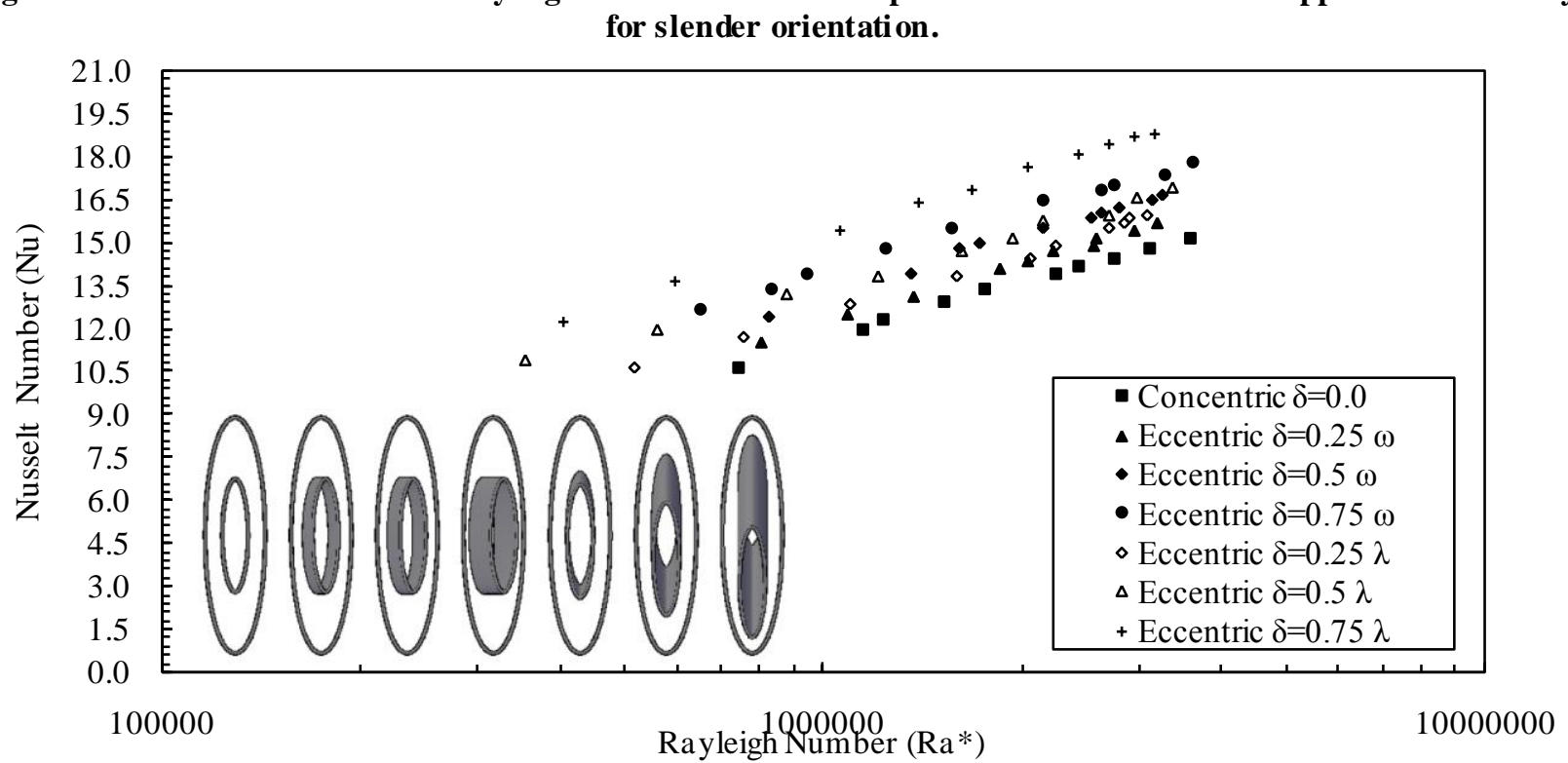

Figure 9 : Nusselt number versus Rayleigh number for the test s pecimen No. III in different opposed eccentricity

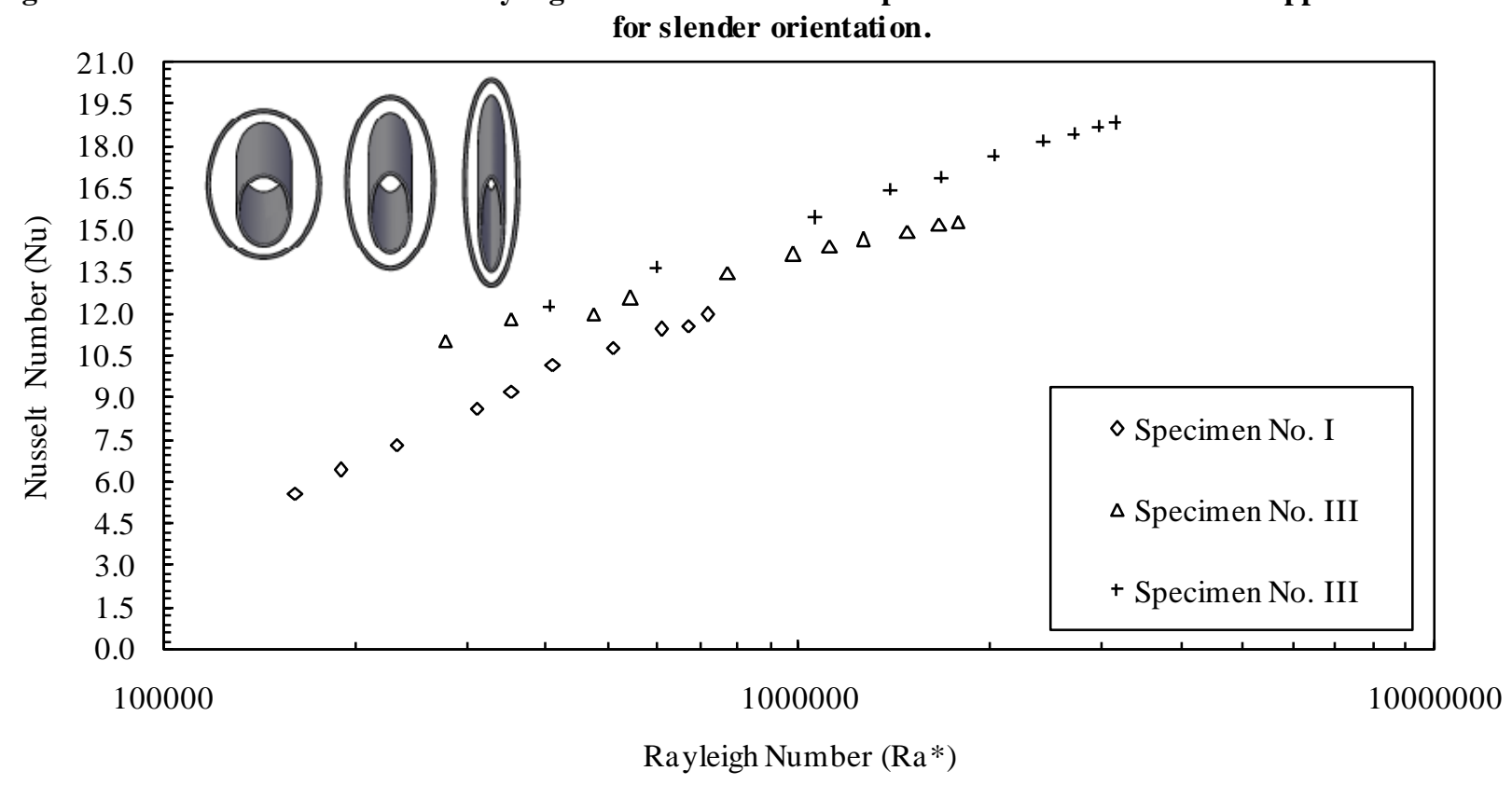

Figure 10 : Nusselt number versus Rayleigh number for the three test s pecimen Eccentric $(\delta=0.75 \lambda)$ for slender orientation. 


\subsection{Blunt Orientation}

Referring to figures $(11,12,13,14)$; the opposed lateral eccentricity results is increasing convective heat transfer. This is attributes to the heterogeneous temperature distribution on both outer surfaces of the inner elliptical cylinder and inner one of the outer one. The heterogeneity produces an additional perpendicular circulatory to the cross section of the test specimen. The crossing of both circulators parallel and perpendicular to cross section creates turbulence regions in the enclosure and as a consequence the convective heat transfer increases. The rapid circulatory of the air plume in the enclosure resulted from the low resistance to the upward driven plume as seen for specimen No. I. The low resistance is resulted from the minimum blockage ratio for the small value of minor axis. The velocity of the upward plume reduces gradually as the blockage ratio increases due to the increase of minor axis as seen from the results of Specimen No. II and III. The higher opposed eccentricity has a significant increase in the convective heat transfer in blunt orientation (vertical eccentric, lateral eccentric). As well as the comparison among vertical opposed eccentric and lateral opposed eccentric for each test specimens in slender orientation gives the same tendency, as clear in figures $(11,12,13)$ that the convective heat transfer for the lateral opposed eccentricity is greater than the convective heat transfer for the vertical opposed eccentricity by about $30 \%$ from concentric. The comparison among the maximum opposed lateral opposed eccentricity $(\delta=0.75 \omega)$ for three test specimens in blunt orientation, figure 14, shows that the convective heat transfer for test specimen No. I is the greatest one

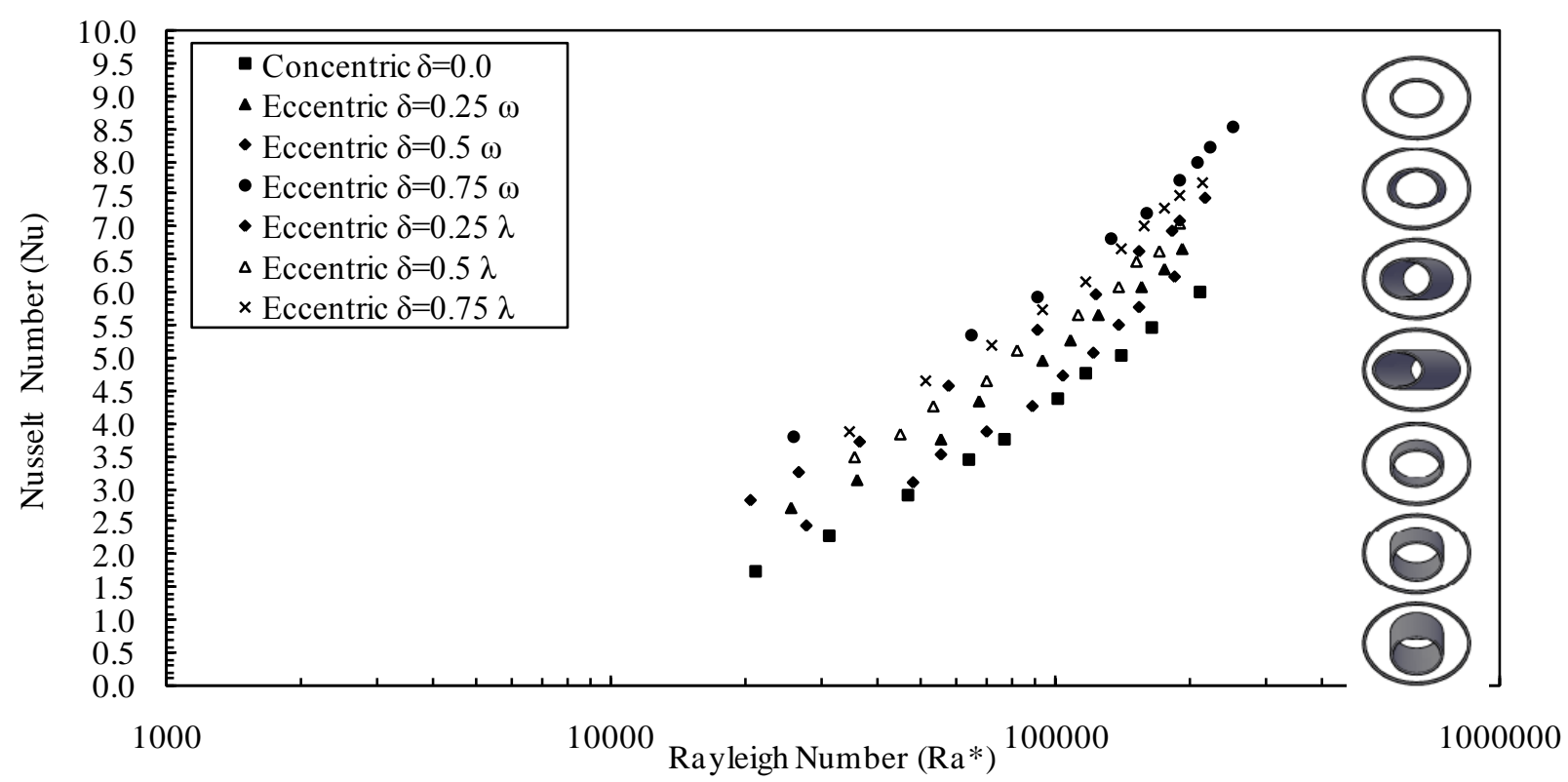

Figure 11 Nusselt number versus Rayleigh number for the test s pecimen No. I in different opposed eccentricity for bl unt orientation.

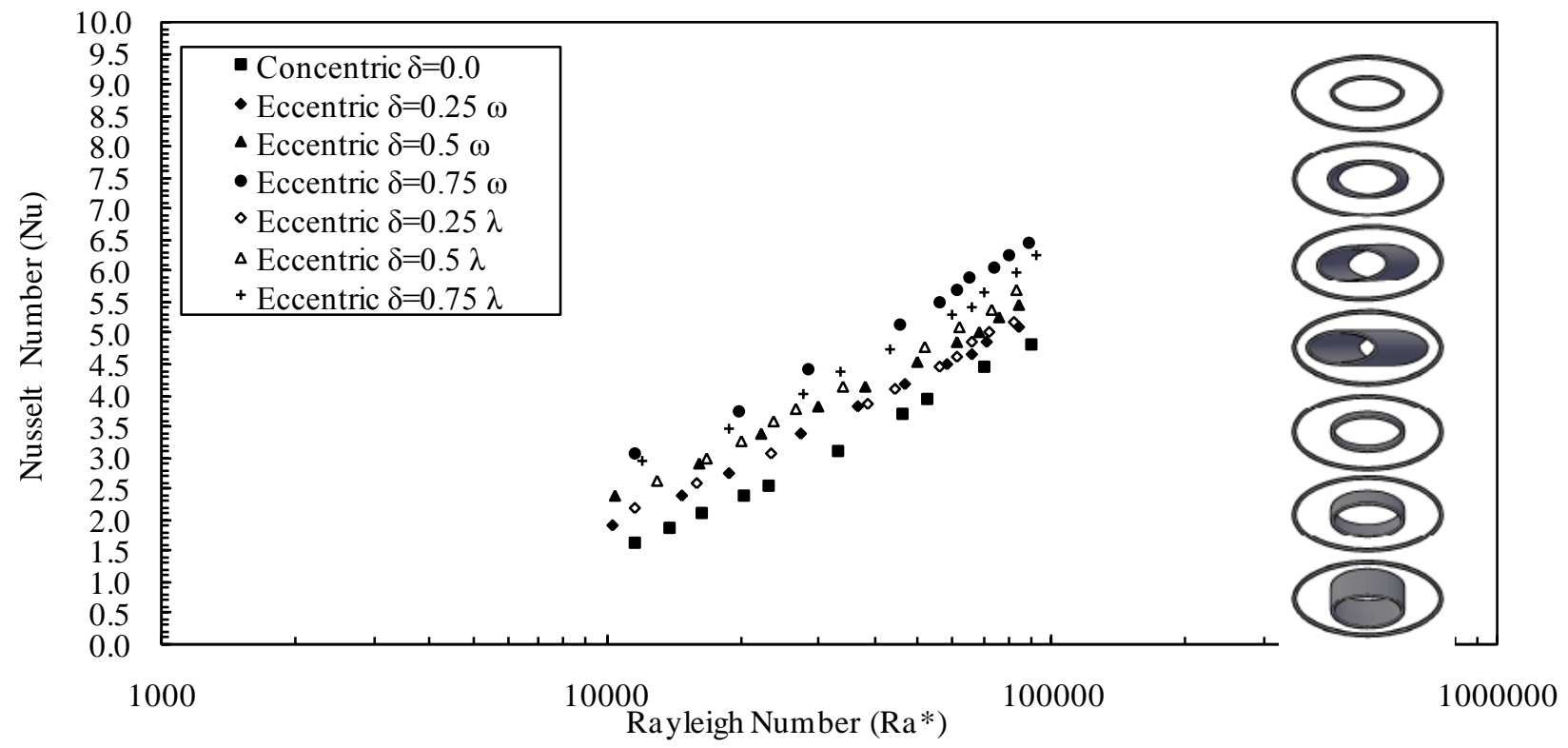

Figure 12 Nusselt number versus Rayleigh number for the test s pecimen No. II in different opposed eccentricity for bl unt orientation. 


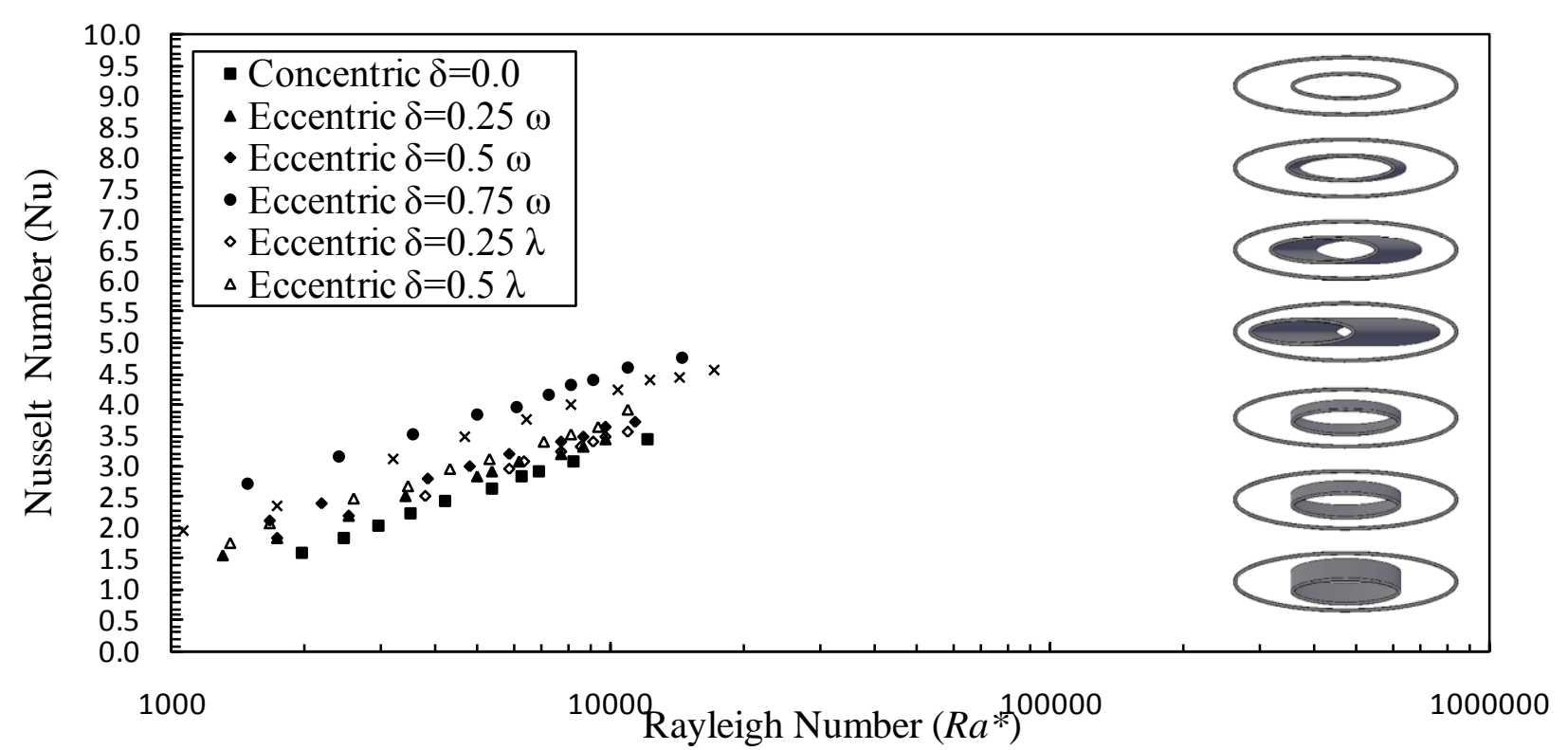

Figure 13 Nusselt number versus Rayleigh number for the test s pecimen No. III in different opposed eccentricity for blunt orientation.

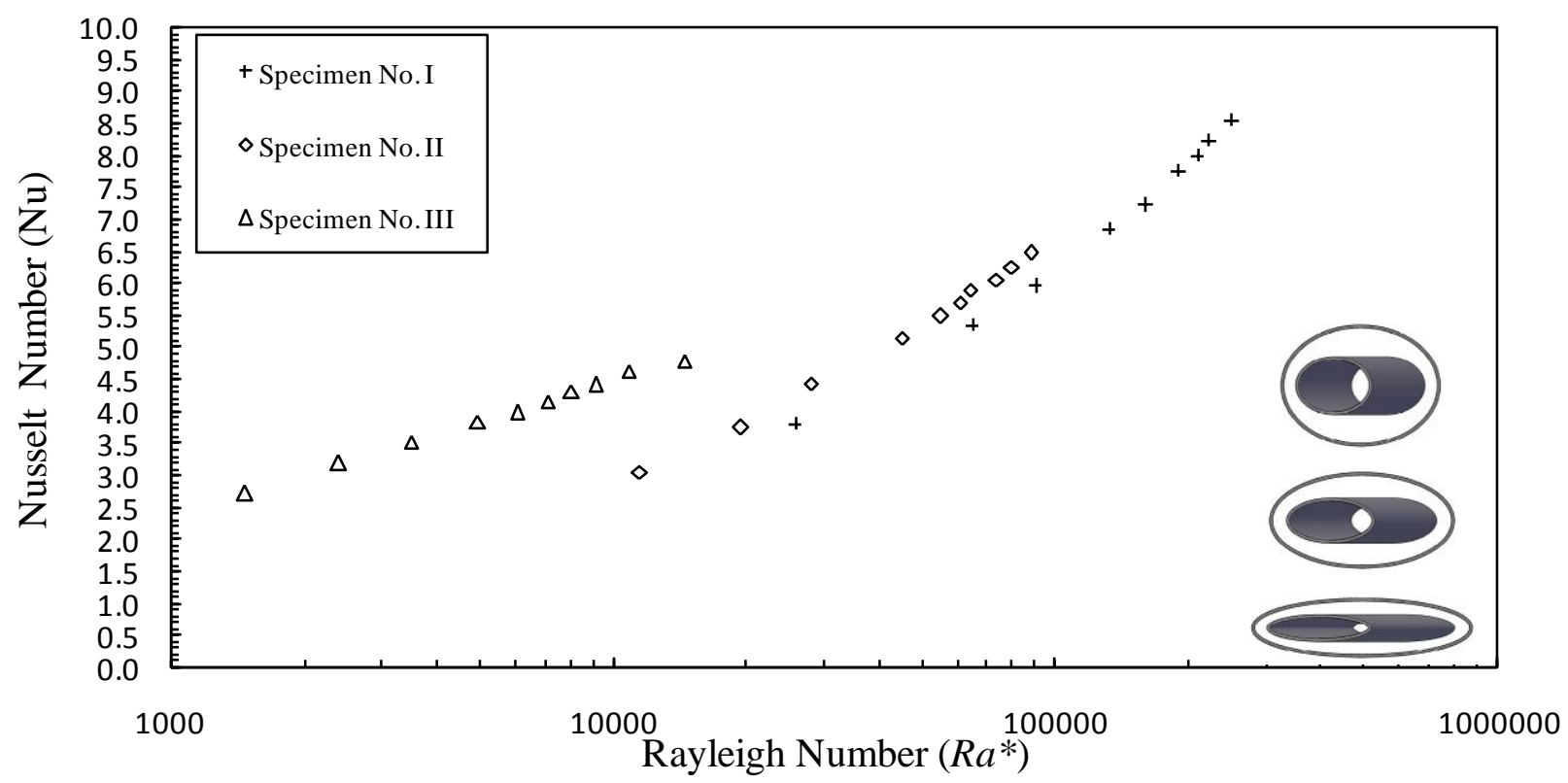

Figure 14 Nusselt number versus Rayleigh number for the three test specimen Eccentric $(\delta=0.75 \omega)$ for blunt orientation.

\subsection{Comparison among Present Results and Previous Ones}

Figure 15 shows a compatible and satisfactory agreement between present experimental results and previous results. The figure shows that the opposed lateral eccentricity for slender orientation offers about $30 \%$ enhancement in free convection than the other cases. 


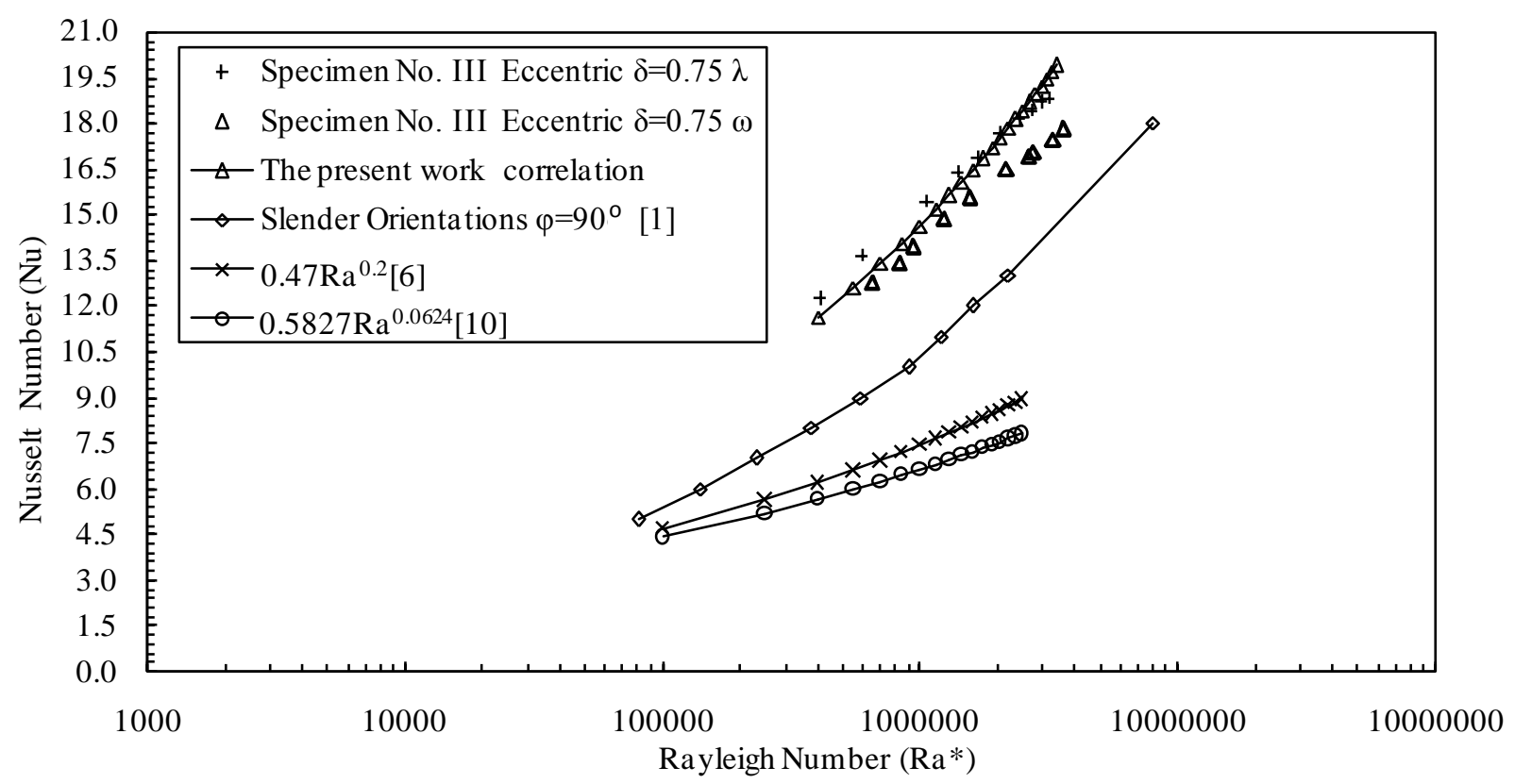

Figure 15 Comparison among present and previous works.

The experimental results were correlated by using the LAB FIT software within uncertainty of about $4.6 \%$.

$$
N u=A R a^{b}\left(\frac{\delta}{\lambda}\right)^{c}\left(\frac{\delta}{\omega}\right)^{d} \xi^{e}
$$

For the next ranges;

Rayleigh Number $8.529 \times 102 \leq \mathrm{Ra}^{*} \leq 3.628 \times 106$

Elliptical ratio $0.662 \leq \xi \leq 0.968$

Opposed vertical eccentric ity $\pm 0.25 \leq \delta / \lambda \leq \pm 0.75$

Opposed lateral eccentricity $\pm 0.25 \leq \delta / \omega \leq \pm 0.75$.

Table 2 Constants, A, b, c, d and e in the deduced empirical correlation for slender orientation

\begin{tabular}{|l|l|l|l|l|l|}
\hline orientation & $\boldsymbol{A}$ & $\boldsymbol{b}$ & $\boldsymbol{c}$ & $\boldsymbol{d}$ & $\boldsymbol{e}$ \\
\hline Concentric & 0.138 & 0.317 & 0 & 0 & 0.770 \\
\hline $\begin{array}{l}\text { Opposed lateral } \\
\text { ecentricity }\end{array}$ & 0.300 & 0.278 & 0 & 0.127 & 0.678 \\
\hline $\begin{array}{l}\text { Opposed virtical } \\
\text { ecentricity }\end{array}$ & 0.498 & 0.250 & 0.215 & 0 & 0.699 \\
\hline
\end{tabular}

Table 3 Constants, A, b, c, $d$ and $e$ in the deduced empirical correlation for bl unt orientation

\begin{tabular}{|l|l|l|l|l|l|}
\hline orientation & $\boldsymbol{A}$ & $\boldsymbol{b}$ & $\boldsymbol{c}$ & $\boldsymbol{d}$ & $\boldsymbol{e}$ \\
\hline Concentric & 0.102 & 0.352 & 0 & 0 & 0.854 \\
\hline $\begin{array}{l}\text { Opposed lateral } \\
\text { eccentricity }\end{array}$ & 0.330 & 0.272 & 0 & 0.278 & 0.136 \\
\hline $\begin{array}{l}\text { Opposed vertical } \\
\text { ecentricity }\end{array}$ & 0.274 & 0.287 & 0.190 & 0 & 0.500 \\
\hline
\end{tabular}

\section{CONCLUSION}

In the present work, free convection in an elliptical annulus enclosure between two elliptical cylinders having different elliptical ratios in blunt and slender orientation was studied experimentally. The study scanned the effects of opposed lateral and vertical eccentricity on free convection for each specimen. The main Results can be briefly systemized as the following items:

1. The convective heat transfer through elliptical annulus enclosure for the opposed vertical eccentricity is greater than the convective heat transfer for the lateral opposed eccentricity in slender orientation by about $40 \%$ from concentric orientation.

2. The comparison among the maximum vertical opposed eccentricity $(\delta=0.75 \lambda)$ for the three test specimens in slender orientation, shows that the convective heat transfer for the test specimen having large Elliptical ratio is greatest one.

3. The convective heat transfer for the opposed lateral eccentricity is greater than the convective heat transfer for the vertical opposed eccentricity in blunt orientation by about $30 \%$ from concentric orientation.

4. The comparison among the maximum lateral opposed eccentricity $(\delta=0.75 \omega)$ for three test specimens in blunt orientation, shows that the convective heat transfer for the test specimen small Elliptical ratio is the greatest one.

5. Slender orientation offers about $50 \%$ enhancement in free convection than the blunt situation for the same elliptical ratio.

\section{REFERENCES}

[1] Eid EI "Experimental study of free convection in an elliptical annular enclosure in blunt and slender orientations" Heat Mass Transfer 47, 8191, (2011).

[2] U. Projahn and H. Beer "Prandtl number effects on natural convection heat transfer in concentric and eccentric horizontal cylindrical annuli" Wãirme- und Stofftibertragung 19, 249-254, (1985).

[3] T. Yousefi , M. Ashjaee "Experimental study of natural convection heat transfer from vertical array of isothermal horizontal elliptic cylinders" Science Direct 32, 240-248, (2007).

[4] Wang Suofang "An Experimental and Numerical Study of Natural Convection Heat Transfer in 
Horizontal Annuli between Eccentric Cylinders" Thermal Science Vol.4, No.1, (1995).

[5] H. Z. Li it all Experimental study of natural convection heat transfer between an outer horizontal cylindrical envelope and an inner concentric heated square cylinder with two slots Heat and Mass Transfer 30 ,455-459,( 1995).

[6] Amr O. Elsayed, it all "Free convection from a constant heat flux elliptic tube" Energy Conversion and Management 44, 2445-2453, (2003).

[7] A. Berkengetm "A Study of Natural Convection in Horizontal Cylindrical Gaps" Orig inal article Vol. 25, No. 4, (1973).

[8] Ching-Yang Cheng " A boundary layer analysis of heat transfer by free convection from permeable horizontal cylinders of elliptic crosssection in porous media using a thermal nonequilibrium model" Heat and Mass Transfer 34, 613-622, (2007).

[9] R.Y. Sakr, it al "Experimental and Numerical Investigation of Natural Convection Heat
Transfer in horizontal Elliptic Annuli" Applied Sciences Research, 4(2): 138-155, (2008).

[10] C. J. Ho, et al "A numerical study of natural convection in concentric and eccentric horizontal cylindrical annuli with mixed boundary conditions" Heat and Fluid Flow, Vol. 10, No. 1, (1989)

[11] Y.D. Zhu it all "Numerical simulation of natural convection between two elliptical cy linders using DQ method" International Journal of Heat and Mass Transfer (2004).

[12] Laith Jaafer Habeeb and Akeel Abdullah Mohammed "Natural Convection Heat Transfer in Horizontal Annuli with Inner Elliptic and Circular Cylinder" International Conference on Engineering and Information Technology, (2012).

[13] S.J.D. D’Alessio ,L.A. Fin lay ,J.P. Pascal “Free convection from elliptic cylinders at small Grashof numbers" International Journal of Heat and Mass Transfer (2008) 